\title{
Peripheral neuropathy in patients with human immunodeficiency viral infection at a tertiary hospital in Ghana
}

\author{
Peter Puplampu ${ }^{1} \cdot$ Vincent Ganu ${ }^{2} \cdot$ Ernest Kenu $^{3} \cdot$ William Kudzi ${ }^{4} \cdot$ Patrick Adjei $^{1} \cdot$ Leticia Grize $^{5,6} \cdot$ Michael Käser $^{5,6}$ (D
}

Received: 9 August 2018 / Revised: 1 February 2019 / Accepted: 21 March 2019 / Published online: 26 April 2019

(C) The Author(s) 2019

\begin{abstract}
Peripheral neuropathy $(\mathrm{PN})$ is the most frequent neurological complication in people living with HIV/AIDS. Neurological damage was identified to not only be caused by the viral infection itself but also through neurotoxic antiretroviral therapy (ART). PN is associated with a variety of risk factors; however, detailed knowledge is scarce for sub-Saharan African populations, bearing among the highest HIV/AIDS infection burden.

In a cross-sectional study, we assessed the prevalence of $\mathrm{PN}$ in 525 adult outpatients suffering from HIV/AIDS and admitted to the largest tertiary hospital in Ghana. Through a detailed questionnaire and clinical examination including neurologic assessment and laboratory blood sample testing, this study investigated associations of PN with demographic and health determinants and identified risk factors associated with sensory neuropathy.

The prevalence of PN in the Ghanaian cohort was $17.7 \%$ and increased odd ratios (OR) when patients were taller ( $>1.57 \mathrm{~m}$; $\mathrm{OR}=3.84 ; 95 \%$ CI 1.38-10.66) or reached the age $>34$ years $(p=0.124)$. Respondents with longer education duration had significantly less PN ( $\geq 9$ years of education; OR $=0.49 ; 95 \%$ CI 0.26-0.92). The study also identified significant association of PN to both waist and hip girth and neutrophil counts. Curiously, higher adjusted odd ratios (aOR) of PN of patients under ART treatment were observed when CD4 lymphocytes were elevated (aOR $=0.81$; 95\% CI 0.36-1.83 and aOR $=2.17$; 95\% CI 0.935.05 , for 300 and 600 counts, respectively). For patients on ART, an increase of 10 CD4 cell count units increased their chance of developing $\mathrm{PN}$ by $1 \%(\mathrm{aOR}=1.01 ; 95 \% \mathrm{CI} 1.00$ to 1.03$)$.

Despite current drug application regulations, prevalence of PN is still unacceptably high in sub-Saharan African populations. Reduction in chronic morbidity through a health system with routine monitoring, early diagnosis and prompt intervention, and effective case management can improve people living with HIV/AIDS' quality of life.
\end{abstract}

Keywords Peripheral neuropathy $\cdot$ PN $\cdot$ Human immunodeficiency virus $\cdot$ HIV-AIDS $\cdot$ Prevalence $\cdot$ Side effect $\cdot$ Antiretroviral therapy $\cdot$ ART $\cdot$ People living with HIV/AIDS $\cdot$ PLHIV $\cdot$ Biothesiometer · NRTI $\cdot$ Protease inhibitor $\cdot$ Sensory neuropathies

Electronic supplementary material The online version of this article (https://doi.org/10.1007/s13365-019-00743-0) contains supplementary material, which is available to authorized users.

Michael Käser

m.kaeser@unibas.ch

1 Department of Medicine, School of Medicine and Dentistry, College of Health Sciences, University of Ghana, Accra, Ghana

2 Department of Medicine, Korle-Bu Teaching Hospital, Accra, Ghana

3 Department of Epidemiology, School of Public Health, University of Ghana, Accra, Ghana

4 Centre for Tropical Clinical Pharmacology and Therapeutics, School of Medicine and Dentistry, College of Health Sciences, Accra, Ghana

5 Swiss Tropical and Public Health Institute, Socinstr. 57, 4002 Basel, Switzerland

6 University of Basel, Petersplatz 1, 4003 Basel, Switzerland

\section{Introduction}

Peripheral neuropathy $(\mathrm{PN})$ in its diverse forms has been reported as the most frequent neurological disorder found in patients with human immunodeficiency viral infection (Keswani et al. 2002; Morgello et al. 2004; McArthur et al. 2005; Ellis et al. 2010). Damage of the nerve fibers caused by the virus first appears in the lower extremities, impedes sensory capacity and mobility and is often painful (Harrison and Smith 2011; Cherry et al. 2012). Impairment in quality of life is often underestimated and the adverse change in lifestyle often culminates in psychological impact including depression (Griswold et al. 2005; Robinson-Papp et al. 2010; Shaikh et al. 2013; Phillips et al. 2014; Pillay et al. 2018).

Sadly, PN was not only shown to be associated with HIV infection itself but also in many cases triggered by the respective 
treatment with antiretroviral agents (Keswani et al. 2002; Cornblath and Hoke 2006; Cherry et al. 2012; Schutz and Robinson-Papp 2013; Margolis et al. 2014). The introduction of antiretroviral therapy (ART) has led to significant worldwide reduction of morbidity and mortality caused by HIV/AIDS (Scanlon and Vreeman 2013; UNAIDS 2016). Recommended as initial treatment are nucleoside reverse-transcriptase inhibitors (NRTIs), followed by integrase strand transfer inhibitors, and boosted by protease inhibitors or combinations thereof (Kamerman et al. 2015; Gunthard et al. 2016). Growing evidence of occurring unwanted side complications through exposure to these medications has led to increasing use of safer ART in many countries (World Health Organisation 2015; Ngassa Mbenda et al. 2017).

Still, PN remains prevalent as the most common neurological disorder among people living with HIV/AIDS (PLHIV). A number of studies show that HIV-PN is experienced by $30-60 \%$ of PLHIV, surely counting up to several millions of affected worldwide (Ferrari et al. 2006; Evans et al. 2008; Ghosh et al. 2012; Kamerman et al. 2012; Cherry et al. 2016). Albeit rates of sensory neuropathies among HIV patients were reported particularly high in African cohorts (Boulle et al. 2007; Forna et al. 2007; Hawkins et al. 2007; Hoffmann et al. 2008; Mehta et al. 2010), PN is both underdiagnosed and undertreated in low- and middle-income countries. Owing to the fact that sub-Saharan Africa has the highest population of affected PLHIV, scarce PN prevalence data from the African continent indicates a large underrepresentation of research including these population groups (Kamerman et al. 2012; Arenas-Pinto et al. 2016; Ngassa Mbenda et al. 2017).

This study was performed in the largest tertiary referral hospital in Ghana, West Africa, between 2013 and 2014. To our knowledge, this is the first investigation of PN prevalence among PLHIV in Ghana. From our routine clinical management of HIV-PN patients admitted to the health facility, we had strong presumptions on (i) a relatively high prevalence of PN developing in PLHIV, (ii) an association with the medication given in accordance with the guidelines of the National AIDS Control Programme regulations, and (iii) we had assumptions, but no information, on health determinants being associated with PN onset among the patients attending. Once a diseased person develops the condition of a sensory disorder, clinicians face challenges to manage the case, and prevention of PN would both decrease disability and lower the costs of local health care. Therefore, in this study, we (i) sought to quantitatively determine PN prevalence among PLHIV at the referral health facility in Ghana, (ii) determine associations of PN development with demographic and health determinants, and (iii) identify and confirm potential risk factors, including ART, in a West African setting.

For this, we studied parameters in a cohort of PLHIV developing PN including demographic parameters, anthropogenic variables, behavioral aspects, and clinical findings. PN manifestation was assessed through quantitative measurement applying the biothesiometer instrument, and blood samples were collected from the study subjects for downstream analysis of laboratory parameters.

\section{Methods}

\section{Study design}

For this work, a hospital-based cross-sectional study was conducted at the Korle-Bu Teaching Hospital (KBTH) in Accra, the largest tertiary hospital in Ghana, with a capacity of 2000 beds and an outpatient department attendance of over 350,000 in 2016. Patients were recruited from the adult HIV outpatient clinic at the infectious disease unit attending about 19,000 PLHIV at the time of the study, 7000 of which being on ART. Out of the pool of regular attendants to the outpatient clinic, the study population was recruited. Patients were informed on objectives and goal of the study, and informed consent was sought for each participant in written form for involvement in the study. Inclusion criteria encompassed adults with more than 18 years of age who regularly attend the infectious disease unit and were diagnosed with HIVAIDS. Diagnosis of HIV was made at the infectious unit by antibody detection on blood samples followed by laboratory confirmation using the OraQuick test according to the Ghana National AIDS Control Programme guidelines. A participant was declared positive for HIV if both tests were positive. The sample size was estimated using StatCalc (Epi Info 2002) computer software considering the following parameters: (i) population size of Greater Accra 2,500,000, (ii) expected a frequency of HIV-PN $=5 \%$, and (iii) worst acceptable result $=$ $1 \%$. StatCalc yielded a sample size of 114 at a confidence level of $95 \%$. Assuming 20\% (i.e., 23) non-participation/ non-response, the total sample size then would be $114+$ $23=137$. An extra number of 163 patients were added to make a total of at least 300. Participants were recruited by systematic random sampling with five patients per day inviting the first patient of each full hour. None of the patients which were sought for enrollment declined consent. Altogether, 525 HIV-positive patients were recruited to participate in the study between 2013 and 2014.

\section{Collection of socio-demographic and clinical data}

Following informed written consent, a questionnaire was administered by a trained research assistant to the participant in order to systematically obtain the following information: sex, age, level of education, employment status, and alcohol and tobacco consumption. Consequently, participants underwent clinical examination to ascertain information on diabetes, hypertension, and any history thereof. Anthropogenic 
measurements were taken to document height, weight, hip girth, and waist girth.

\section{Biothesiometric examination}

As part of the physical examination, the use of a biothesiometer was applied in order to diagnose PN as objectively as possible. A handheld biothesiometer (BioMedical Instruments, Newbury, OH, USA) which vibrates at $100 \mathrm{~Hz}$ when operating on $50 \mathrm{~Hz}$ mains was applied to measure the vibration perception threshold (VPT) to determine neurological deficits and for which we expected both specificity and sensitivity of above 70\% (Yajnik et al. 2012; Gill et al. 2014). Impaired VPT was measured in three recordings on the plantar aspect of the distal phalanx of the big toe. Each participant was seated in a comfortable and relaxed position and was made to feel the vibration sense of the biothesiometer and to report the initial feel by saying "yes". The device was held steadily over the testing site such that the weight of the vibrator exerts a standard pressure. The amplitude of the vibration was gradually increased from zero to a maximum of $50 \mathrm{~V}$. For participants who were unable to feel any vibration even at the maximum amplitude, the value of $50 \mathrm{~V}$ was recorded. In order to circumvent usage variation and interpretation of the biothesiometer by different physicians, training on the device was given prior to the onset of the investigation. A VPT value of $>9 \mathrm{~V}$ was defined as the manifestation of PN.

\section{Laboratory analysis}

Fasting blood samples were collected from each participant for further laboratory analysis at a local commercial laboratory facility. Blood was tested for lipoprotein, lactate, hemoglobin, and fasting glucose. CD4 leukocytes were counted, as were neutrophils.

\section{Data entry}

Documentation of the study included the study protocol, the investigators' log sheet, the patients' log sheet, the informed consent, and the questionnaire. From the paper-based and filled case report form, data were entered into the Epi Info software and combined with data retrieved from laboratory analyses. Captured data per participant was cleaned and data transfer periodically checked by trained personnel, followed by application of blinding methodology. Subsequently, data entry of $53(10 \%)$ randomly selected subjects of the 525 patient documentations was reproduced by a person that was neither involved in the study nor in data entry. Among those, only two parameters of the whole raw data set differed which had no impact on the analysis. This random test confirmed the reliability of the entire data set for further analysis.

\section{Statistical analysis}

Continuous factors were summarized as means and standard deviations and categorical factors as counts and proportions. Categorized data were additionally analyzed using underlying continuous values in order not to reduce statistical power.

Medians and interquartile ranges were also calculated but are not presented. In order to examine the association between potential risk factors of PN, firstly, unadjusted comparisons were calculated. Unadjusted comparisons were done using a Chisquare test or Fisher's exact test if the parameter was categorical, and the Mann-Whitney $U$ test if the parameter was continuous. In a second step, multivariable logistic regressions were performed to determine the associations between $\mathrm{PN}$ as a binary variable and potential risk factors. Factors known from the literature to have an association with PN and factors with an unadjusted association at $p<0.20$ were included in the initial multivariable model. The risk factors included in the initial model were being on ART, change of ART medication, patient's sex and age, education, height and height to weight ratio, hip and waist girth, lactate, chromium concentration, neutrophils and lymphocytes, and CD4 cell counts. The model was reduced using backwards selection with a threshold alpha of 0.25 . The statistical software SAS version 9.4 (2002-2012, SAS Institute Inc., Cary, NC, USA) was used to perform the analysis. Statistical significance was set to an alpha level of 0.05 . The dataset was not complete for all parameters throughout the 525 subjects, and therefore, almost one-third of the subjects could unfortunately not be included in the multivariable analyses. In a sensitivity analysis, in order to examine the effect of the absence of those respondents, inverse probability weights were calculated and included in the logistic regression, and results were compared to those from the main analysis.

\section{Results}

A total of 525 HIV-positive study participants were recruited for the study. Four hundred and thirty-seven $(84.4 \%)$ were female; $81(16.6 \%)$ were male. The mean age was $33.6 \pm 4.9$ with the minimum and maximum age of 19 and 40, respectively. Results are outlined in Table 1 including education and employment status, behavioral aspects (consumption of alcohol and tobacco), and body measurements (height, weight, and hip and waist girth). The mean BMI was calculated as $23.9 \pm 4.9$ and ranged from 11.3 to 44.6 (not shown). Table 1 also lists laboratory measures encompassing CD4 cell counts, lipoprotein, lactate, hemoglobin, and fasting glucose values.

Of the 525 respondents, $314(59.8 \%)$ were on ART. Out of these 314 patients on ART, 281 could give information on the duration on ART, ranging between 1 to 248 months and with the mean of $39.9 \pm 30.4$ months. Table 2 shows the ART regimen groups administered to the enrolled patients. The prevalence of 
Table 1 Socio-demographic and clinical characteristics: distribution of patients with HIV at a tertiary hospital in Ghana, stratified by receiving ART or not

\begin{tabular}{|c|c|c|c|c|}
\hline Characteristic & $\begin{array}{l}\text { Total }(n=525) \\
n(\%)\end{array}$ & $\begin{array}{l}\text { On ART }(n=314) \\
n(\%)\end{array}$ & $\begin{array}{l}\text { Not on ART }(n=211) \\
n(\%)\end{array}$ & $p$ value* \\
\hline Sex & & & & $<0.001$ \\
\hline Male & $81(15.6)$ & $34(11.0)$ & $47(22.6)$ & \\
\hline Female & $437(84.4)$ & $276(89.0)$ & $161(77.4)$ & \\
\hline Age $($ mean \pm SD $)$ & $33.6 \pm 4.9$ & $34.6 \pm 4.3$ & $32.0 \pm 5.4$ & $<0.001$ \\
\hline Education & & & & 0.019 \\
\hline None & $88(17.1)$ & $61(19.7)$ & $27(13.1)$ & \\
\hline$\leq 9$ years & $253(49.0)$ & $154(49.7)$ & $99(48.1)$ & \\
\hline $9-12$ years & $123(23.8)$ & $72(23.2)$ & $51(24.8)$ & \\
\hline$>12$ years & $50(9.7)$ & $21(6.8)$ & $29(14.1)$ & \\
\hline Others & $2(0.4)$ & $2(0.7)$ & $0(0)$ & \\
\hline Employment status & & & & 0.302 \\
\hline Unemployed & $104(20.5)$ & $62(20.5)$ & $42(20.6)$ & \\
\hline Part-time & $22(4.3)$ & $14(4.6)$ & $8(3.9)$ & \\
\hline Full-time employment & $365(72.0)$ & $221(72.9)$ & $144(70.6)$ & \\
\hline Retired and not working & $0(0)$ & $0(0)$ & $0(0)$ & \\
\hline Retired but working & $1(0.20)$ & $0(0)$ & $1(0.5)$ & \\
\hline $\begin{array}{l}\text { Lost employment when status } \\
\text { was discovered }\end{array}$ & $1(0.20)$ & $1(0.33)$ & $0(0)$ & \\
\hline Too weak to continue working & $14(2.8)$ & $5(1.7)$ & $9(4.4)$ & \\
\hline Alcohol consumption & & & & $<0.001$ \\
\hline Yes, currently & $52(10.0)$ & $14(4.5)$ & $38(18.2)$ & \\
\hline No & $469(90.0)$ & $298(95.5)$ & $171(81.8)$ & \\
\hline Smoking status & & & & 0.209 \\
\hline Current smoker & $10(1.9)$ & $4(1.3)$ & $6(2.9)$ & \\
\hline Non/ex-smoker & $512(98.1)$ & 309 (98.7) & $203(97.1)$ & \\
\hline Height $(\mathrm{cm}$, mean \pm SD) & $162.7 \pm 8.0$ & $161.8 \pm 7.9$ & $163.9 \pm 8.1$ & 0.002 \\
\hline Weight $(\mathrm{kg}$, mean $\pm \mathrm{SD})$ & $63.5 \pm 13.4$ & $64.1 \pm 13.0$ & $62.6 \pm 14.0$ & 0.172 \\
\hline Hip girth $(\mathrm{cm}$, mean $\pm \mathrm{SD})$ & $79.1 \pm 30.8$ & $89.8 \pm 25.3$ & $63.7 \pm 31.5$ & $<0.001$ \\
\hline Waist girth $(\mathrm{cm}$, mean $\pm \mathrm{SD})$ & $66.8 \pm 27.0$ & $73.3 \pm 22.0$ & $53.4 \pm 27.7$ & $<0.001$ \\
\hline Peripheral neuropathy & & & & 0.201 \\
\hline Yes & $93(17.7)$ & $50(15.9)$ & $43(20.4)$ & \\
\hline No & $432(82.3)$ & $264(84.1)$ & $168(79.6)$ & \\
\hline $\mathrm{CD} 4$ cell count $($ mean $\pm \mathrm{SD})$ & $448.2 \pm 271.8$ & $493.1 \pm 255.7$ & $385 \pm 281.8$ & $<0.001$ \\
\hline Low-density lipoprotein $(\mu \mathrm{mol} / 1$, mean $\pm \mathrm{SD})$ & $3.1 \pm 0.9$ & $3.3 \pm 0.9$ & $2.9 \pm 0.9$ & $<0.001$ \\
\hline High-density lipoprotein $(\mu \mathrm{mol} / \mathrm{l}$, mean $\pm \mathrm{SD})$ & $1.3 \pm 0.4$ & $1.5 \pm 0.4$ & $1.1 \pm 0.3$ & $<0.001$ \\
\hline Lactate $(\mathrm{mmol} / \mathrm{l}$, mean $\pm \mathrm{SD})$ & $1.8 \pm 0.4$ & $1.7 \pm 0.4$ & $1.9 \pm 0.3$ & $<0.001$ \\
\hline Hemoglobin $(\mathrm{g} / \mathrm{dl}$, mean $\pm \mathrm{SD})$ & $11.9 \pm 1.7$ & $12.0 \pm 1.6$ & $11.8 \pm 1.8$ & 0.049 \\
\hline Fasting glucose $(\mathrm{mmol} / \mathrm{l}$, mean $\pm \mathrm{SD})$ & $4.7 \pm 0.6$ & $4.7 \pm 0.7$ & $4.7 \pm 0.5$ & 0.800 \\
\hline
\end{tabular}

*Chi-square or Fisher's exact test was used if characteristic was categorical and Mann-Whitney $U$ test if continuous $A R T$, antiretroviral therapy; $S D$, standard deviation

Peripheral neuropathy $=$ vibration perception threshold $>9 \mathrm{~V}$, base of first toe (left and right; average of three measurements)

PN among study participants was $17.7 \%$ - 93 of the 525 subjects were diagnosed with the neurological disorder above the VPT using the biothesiometer. Of the 93 respondents with diagnosed $\mathrm{PN}, 50$ were on AR therapy and 43 were not.
Table 3 outlines, in an unadjusted manner, potential association between PN and anthropometric, socioeconomic, and clinical characteristics of HIV-positive respondents. Factors of statistical significance $(p<0.05)$ towards development of PN include 
Table 2 Descriptive statistics of the administered ART regimen for all subjects, stratified by PN status

\begin{tabular}{llll}
\hline Abbreviation & ART regimen & PN status & $\begin{array}{l}\text { All patients }(n=525) \\
n(\%)\end{array}$ \\
\hline NRTI & Nucleoside reverse transcriptase inhibitors & No PN & $218(41.52)$ \\
& & PN & $307(58.47)$ \\
NNRTI & Non-nucleoside reverse transcriptase inhibitors & No PN & $235(44.76)$ \\
& & PN & $290(55.23)$ \\
PI & Protease inhibitors & No PN & $512(97.52)$ \\
& & PN & $13(2.476)$ \\
\hline
\end{tabular}

PN (peripheral neuropathy) $=$ vibration perception threshold $>9 \mathrm{~V}$, base of first toe (left and right; average of three measurements) (i) body height, (ii) waist girth, (iii) hip girth, (iv) neutrophil counts, (v) lymphocyte counts, and (vi) chromium level.

Multivariable analyses of PN with ART and other risk factors are shown in Table 4. Re-analyses of the data on height and age using continuous variables give the same results.

Surprisingly, the study found a significant association between being on ART and CD4 cell counts $(p=0.007)$. In the presence of an interaction, both antiretroviral (AR) medication and CD4 cells had an effect on PN development ( $p=0.066$ and $p=0.033$, respectively). For patients on ART, an increase of 10 CD4 cell count units increased their chance of developing PN by $1 \%$ (adjusted odd ratio $(\mathrm{aOR})=1.01 ; 95 \% \mathrm{CI} 1.00$ to 1.03$)$. In contrast, for patients not on ART, such increase of 10 units in CD4 cell counts decreased their chance of developing PN by $2 \%$ $(\mathrm{aOR}=0.98 ; 95 \%$ CI 0.97 to 1.00$)$ (Table 4). Figure 1 visualizes this interaction between developing PN and being on ART. The aOR are as follows: 0.69 (95\% CI 0.29-1.64) at a CD4 cell count of 250; 1.33 (95\% CI 0.63-2.81) at a CD4 cell count of 450; and 2.17 (95\% CI 0.93-5.05) at a CD4 cell count of 600. Hence, the probability of being diagnosed with $\mathrm{PN}$ - when being on ART or not - in relation to CD4 cell counts could be estimated (Fig. 1).

Statistical significance towards developing PN was also found to be associated with an increase in lactate levels $(p=0.073)$ and with age over 34 years $(p=0.124)$. Instead, patients with $>$ 9 years of education have a lower risk of suffering PN ( $p=$ 0.027). With a statistically significant overall effect of body height on PN $(p=0.007)$, study participants between 1.57$1.62 \mathrm{~m}$ of height had 3.84 times the aOR of developing PN compared to those with heights $\leq 1.57 \mathrm{~cm}$ (95\%CI 1.38 to 10.66). This aOR increases to 4.89 and 5.74 times the aOR of subjects between $1.62-1.66 \mathrm{~m}$ (95\% CI 1.69 to 13.66$)$ and $>$ $1.66 \mathrm{~m}$ (95\% CI 2.11 to 15.62$)$, respectively.

No statistical significance among PLHIV with PN was found in sex, age, education and employment status, alcohol and tobacco consumption, or weight. Sensitivity analysis using inverse probability weighting to examine the effect in patient datasets with missing information did not show different associations than the presented model (see Table S1 in the supplementary material).

\section{Discussion}

The introduction of antiretroviral medication has drastically reduced morbidity and mortality. Although management of HIV/AIDS cases through the use of ART has improved quality of life and a longer survival, chronic co-morbidities have emerged. Also, increased life expectancy naturally made the HIV-infected population grow older (Scanlon and Vreeman 2013; World Health Organisation 2015; UNAIDS 2016). Hence, the continued high prevalence of sensory neuropathies continues to affect PLHIV and requires clinical and health care attention (Ellis et al. 2010; Schutz and Robinson-Papp 2013).

The present investigation including 525 patients is the largest study on PN so far in Ghana and, to our knowledge, in West Africa, carrying the highest burden of HIV infection worldwide. In an earlier study, PN prevalence was revealed in type 2 diabetes patients in the same setting (Yeboah et al. 2016). The prevalence of PN in this study's subset of individuals admitted to the largest tertiary referral hospital in Ghana in 2013/2014 and infected with HIV/AIDS was $17.7 \%$. This number somewhat ranges within the ratios found in other studies performed in sub-Sahara Africa. Such studies reported prevalence of $6 \%$ and $57 \%$ in South Africa, respectively (Boulle et al. 2007; Wadley et al. 2011), $13 \%$ in Malawi (Beadles et al. 2009), $20.7 \%$ and $36 \%$ in Kenya, respectively (Hawkins et al. 2007; Mehta et al. 2010), $36 \%$ in Uganda (Forna et al. 2007), 24\% in Uganda/Zimbabwe (Kiwuwa-Muyingo et al. 2014), 59\% in Rwanda (Tumusiime et al. 2014a), and 28\% in Cameroon (Luma et al. 2012). A recent study by Benevides et al. 2017 in southern Brazil unveiled $31.3 \%$ of PN prevalence in PLHIV. In some settings, variations in the methodology to diagnose PN even seem to cause overreporting of PN (Tumusiime et al. 2014b).

These obvious differences may originate in the differing nature of the performed studies: (i) the sample sizes differ considerably, with our study representing a respectable patient number, (ii) the inclusion criteria applied, resulting in varying average age of the study subjects, (iii) varying progression stages of the underlying HIV/AIDS infection of the study subjects, (iv) altering diagnostic approaches and procedures applied, (v) the ratio of 
Table 3 Unadjusted associations between peripheral neuropathy (PN) and predicting characteristics in HIV patients $(n=525)$

\begin{tabular}{|c|c|c|c|}
\hline Characteristic & $\begin{array}{l}\mathrm{PN}(n=93) \\
n(\%)\end{array}$ & $\begin{array}{l}\text { No neuropathy }(n=432) \\
n(\%)\end{array}$ & $p$ value* \\
\hline Sex & & & 0.433 \\
\hline Male & $17(18.3)$ & $64(15.1)$ & \\
\hline Female & $78(81.7)$ & $361(84.9)$ & \\
\hline Age $($ mean $\pm \mathrm{SD})$ & $34.1 \pm 4.8$ & $33.5 \pm 5.0$ & 0.284 \\
\hline Education & & & 0.147 \\
\hline None & $13(14.0)$ & $75(17.7)$ & \\
\hline$\leq 9$ years & $55(59.1)$ & $198(46.8)$ & \\
\hline $9-12$ years & $21(22.6)$ & $102(24.1)$ & \\
\hline$>12$ years & $4(4.3)$ & $46(10.9)$ & \\
\hline Others & $0(0.0)$ & $2(0.5)$ & \\
\hline Employment status & & & 0.392 \\
\hline Unemployed & $15(16.3)$ & $89(21.4)$ & \\
\hline Part-time & $4(4.3)$ & $18(4.3)$ & \\
\hline Full-time employment & $69(75.0)$ & $296(71.3)$ & \\
\hline Retired and not working & $0(0.0)$ & $0(0.0)$ & \\
\hline Retired but working & $1(1.1)$ & $0(0.0)$ & \\
\hline Lost employment when status was discovered & $0(0.0)$ & $1(0.24)$ & \\
\hline Too weak to continue working & $3(3.3)$ & $11(2.7)$ & \\
\hline Alcohol consumption & & & 0.450 \\
\hline Yes, currently & $7(7.5)$ & $45(10.5)$ & \\
\hline No & $86(92.5)$ & $383(89.5)$ & \\
\hline Smoking status & & & 0.222 \\
\hline Current smoker & 0.0 & $10(2.3)$ & \\
\hline Non/ex-smoker & $93(100.0)$ & $419(97.7)$ & \\
\hline Height $(\mathrm{cm}$, mean $\pm \mathrm{SD})$ & $1.7 \pm 0.8$ & $1.6 \pm 0.8$ & $<0.001$ \\
\hline Weight $(\mathrm{kg}$, mean $\pm \mathrm{SD})$ & $65.3 \pm 14.5$ & $63.1 \pm 13.2$ & 0.232 \\
\hline Waist girth $(\mathrm{cm}$, mean $\pm \mathrm{SD})$ & $57.1 \pm 28.0$ & $69.0 \pm 26.3$ & 0.002 \\
\hline Hip girth $(\mathrm{cm}$, mean $\pm \mathrm{SD})$ & $67.0 \pm 31.7$ & $81.7 \pm 30.0$ & $<0.001$ \\
\hline \multicolumn{4}{|l|}{ ART } \\
\hline Yes & $50(53.8)$ & $264(61.1)$ & 0.201 \\
\hline No & $43(46.2)$ & $168(38.9)$ & \\
\hline $\mathrm{CD} 4$ cell count $($ mean $\pm \mathrm{SD})$ & $407.3 \pm 247.9$ & $457.3 \pm 276.4$ & 0.236 \\
\hline Low-density lipoprotein $(\mu \mathrm{mol} / \mathrm{l}$, mean $\pm \mathrm{SD})$ & $3.1 \pm 0.9$ & $3.2 \pm 0.9$ & 0.484 \\
\hline High-density lipoprotein $(\mu \mathrm{mol} / \mathrm{l}$, mean $\pm \mathrm{SD})$ & $1.3 \pm 0.5$ & $1.3 \pm 0.4$ & 0.182 \\
\hline Lactate $(\mathrm{mmol} / \mathrm{l}$, mean $\pm \mathrm{SD})$ & $1.9 \pm 0.3$ & $1.8 \pm 0.4$ & 0.072 \\
\hline Hemoglobin $(\mathrm{g} / \mathrm{dl}$, mean \pm SD $)$ & $11.8 \pm 1.7$ & $11.9 \pm 1.7$ & 0.879 \\
\hline Neutrophils (cells/ $\mu 1$, mean \pm SD) & $41.1 \pm 12.6$ & $38.1 \pm 11.7$ & 0.033 \\
\hline Lymphocytes (cells $/ \mu 1$, mean \pm SD) & $48.5 \pm 12.4$ & $51.8 \pm 11.9$ & 0.020 \\
\hline Fasting glucose $(\mathrm{mmol} / \mathrm{l}$, mean $\pm \mathrm{SD})$ & $4.7 \pm 0.5$ & $4.7 \pm 0.6$ & 0.795 \\
\hline Chromium (units, mean \pm SD) & $68.1 \pm 23.5$ & $62.6 \pm 17.7$ & 0.037 \\
\hline
\end{tabular}

*Chi-square or Fisher's exact test was used if characteristic was categorical and Mann-Whitney $U$ test if continuous

$A R T$, antiretroviral therapy; $S D$, standard deviation

PN (peripheral neuropathy) = vibration perception threshold $>9 \mathrm{~V}$, base of first toe (left and right; average of three measurements) subjects being on antiretroviral medication, and (vi) the different type of ART regimen administered to the study cohorts.
With regard to the latter, in many studies, patients were enrolled whilst on NRTIs or protease inhibitors as a first-line 
Fig. 1 PN odd ratios (OR) for patients on ART (yes vs. no) with calculated predicted probability of having $\mathrm{PN}$ in relation to $\mathrm{CD} 4$ cell factors as shown in Table 4). Top panel: OR of diagnosed PN in patients on ART at different CD4 cell counts (knots show the OR; whiskers the $95 \%$ CIs). Bottom panel: effect of the interaction between being on ART and CD4 cell counts on the PN-predicted probability (calculated at the mean values of 65.05 for waist girth, 77.04 for hip girth, lactate $<$ $2.2 \mathrm{mmol} / \mathrm{l}$, a height $<1.57 \mathrm{~m}$, and education of $<9$ years) counts (adjusted for relevant
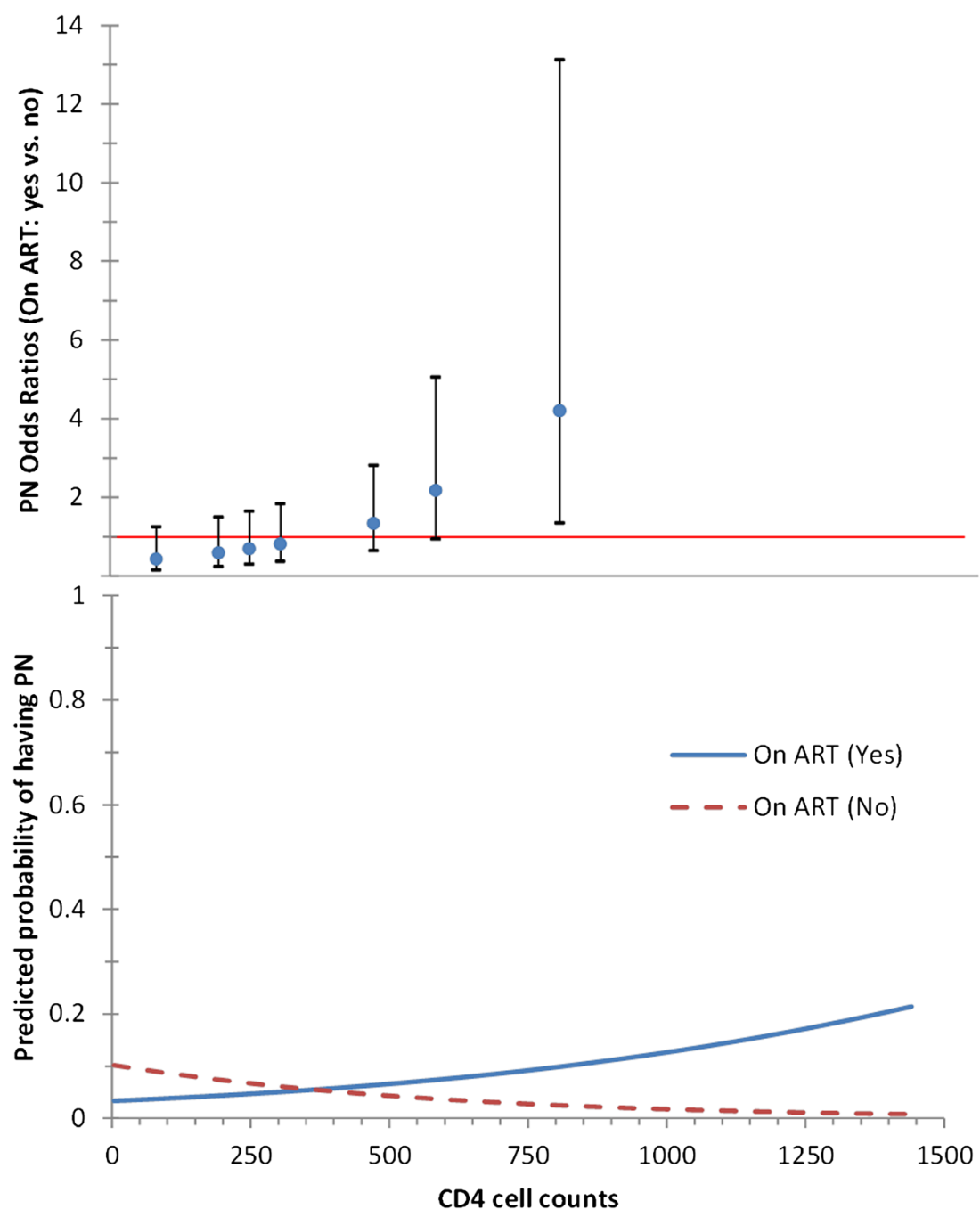

antiretroviral medication. It was repeatedly reported that these drug groups have severe neurotoxic impact, above all stavudine, but also didanosine and zalcitabine (Forna et al. 2007; Hoffmann et al. 2008; Ances et al. 2009; Maritz et al. 2010; Evans et al. 2011; Wadley et al. 2011; Kamerman et al. 2012; Chen et al. 2013; Kiwuwa-Muyingo et al. 2014; World Health Organisation 2015). In Ghana, since inception of the study, the first-line treatment is a combination of two NRTIs and one non-NRTI, followed by a second-line treatment also including a protease inhibitor.

Increased CD4 counts may account for either immunocompetence or viral control due to treatment. Studies on subject under NRTI treatment regimen usually did show low CD4 levels associated with PN whereas later studies, omitting NRTIs and protease inhibitors, tend to show no association between CD4 counts and sensory neuropathies (Evans et al. 2011; Benevides et al. 2017). The underlying mechanisms are unclear and require additional research. Our unusual finding of increased CD4 lymphocytes associated with PN only in HIV infected on ART but not in non-treated patients remains an undecided observation and may be interpreted such that the treatment reduces viral load but continues to negatively affect patients' nervous conditions.

It was reported earlier that women are more affected by development of PN (Collins et al. 2009; Nwabueze et al. 2012; Gomez-Olive et al. 2013; Kimanga et al. 2014; Fagbamigbe et al. 2016) which is confirmed in this study. Nevertheless, this does not necessarily mean that women are more susceptible to development of PN. Women's more prudent health care-seeking behavior when confronted with illness, accounting for a higher detection rate in women, is a likely explanation for this finding.

Accordingly, higher education usually leads to better awareness of both a healthy lifestyle and handling of illness including compliance to medication, and this coincides with this study's findings of a lower risk of PN development in patients with higher education status. Surely, this association supports the aspirations of the sustainable development goals no. 1 "no poverty," no. 4 "quality education," and no. 10 "reduced inequalities" also in this particular diseases. 
Table 4 Multivariable* association of PN with ART and other risk factors $(n=333)$

\begin{tabular}{|c|c|c|c|c|}
\hline Risk factor & Value/level & Adjusted odd ratio & $95 \% \mathrm{CI}$ for $\mathrm{OR}$ & $p$ value \\
\hline Intercept & & & & 0.010 \\
\hline On ART medication & Yes vs. no, at $\mathrm{CD} 4=600$ cells & 2.17 & 0.93 to 5.05 & 0.066 \\
\hline Interaction of on ART and CD4 cell count & & & & 0.007 \\
\hline \multirow[t]{2}{*}{ CD4 cell count } & 10-unit increase for on ART & 1.01 & 1.00 to 1.03 & \multirow[t]{2}{*}{0.033} \\
\hline & 10-unit increase for not on ART & 0.98 & 0.97 to 1.00 & \\
\hline Lactate & $>2.2 \mathrm{vs} . \leq 2.2 \mathrm{mmol} / 1$ & 2.49 & 0.92 to 6.72 & 0.073 \\
\hline Age group & $>34$ years vs. $\leq 34$ years & 1.58 & 0.88 to 2.83 & 0.124 \\
\hline Education group (years of school) & $>9$ years vs. $\leq 9$ years & 0.49 & 0.26 to 0.92 & 0.027 \\
\hline \multirow[t]{3}{*}{ Patient's height (quartiles) ${ }^{\S}$} & $>1.66$ vs. $\leq 1.57 \mathrm{~m}$ & 5.74 & 2.11 to 15.62 & $<0.001$ \\
\hline & $>1.62$ to $1.66 \mathrm{vs} . \leq 1.57 \mathrm{~m}$ & 4.89 & 1.69 to 13.66 & 0.003 \\
\hline & $>1.57$ to $1.62 \mathrm{vs} . \leq 1.57 \mathrm{~m}$ & 3.84 & 1.38 to 10.66 & 0.010 \\
\hline Average waist girth & $1-\mathrm{cm}$ increase & 1.04 & 0.98 to 1.09 & 0.159 \\
\hline Average hip girth & 1-cm increase & 0.96 & 0.92 to 1.00 & 0.054 \\
\hline
\end{tabular}

*A logistic regression model was used. The original model included in addition the factors: change of ART medication, patient's sex, alcohol intake, height to weight ratio, and neutrophils and lymphocyte counts. The model was reduced using backwards selection excluding factors with a $p$ value $>0.25$ ${ }^{\S} p=0.007$ for the overall effect of height

$A R T$, antiretroviral therapy

PN (peripheral neuropathy) determined with vibration perception threshold $>9 \mathrm{~V}$ (base of first toe, left and right; average of three measurements)

Our study revealed that increasing height was independently associated with the risk of developing of PN, reconfirming the findings of other studies. This is probably simply owing to the fact that increased nerve length, and thus a larger axon surface area, may be of greater risk for neurological damage (Cheng et al. 2006; Chen et al. 2013; Kote et al. 2013; Luma et al. 2018).

In contrast to the recently published linkage between use of tobacco and PN development in Brazil (Benevides et al. 2017), our data does not confirm such association.

Age as a risk factor for PN, however, was reported many times before and proved to be so in HIV patients above 34 years of our cohort as well (Evans et al. 2011; Wadley et al. 2011; Nwabueze et al. 2012; Chen et al. 2013; Kiwuwa-Muyingo et al. 2014; Tumusiime et al. 2014a, b). As possible explanation, on the one hand, aging increases vulnerability towards neuronal toxicity, on the other hand is the HIV population's median age rapidly increasing due to continuously improved management of infected persons in Sub-Sahara Africa, and so is the prevalence of PN. Therefore, these results encourage health systems to routinely screen PLHIV for early onset PN of age $>30$ years.

The here determined association between PN in HIV patients with levels of chromium (Head 2006; Kallianpur et al. 2006; Afridi et al. 2014) and lactate (Miller et al. 2002; Brew et al. 2003) as well as elevated counts of neutrophils as compared to CD4 lymphocytes (Ford et al. 2015; Means et al. 2016) indicates that blood testing including these parameters may be a good indicator when assessing early onset development of PN.

Meanwhile, genetic studies made assumptions on singlenucleotide polymorphisms, i.e., in gene CAMKK2, on position rs28445017, or in MTND2*LHON-4917G but possibly also others, being associated with development of PN but this needs further clarification (Canter et al. 2008; Wadley et al. 2015; Goullee et al. 2016; Hendry et al. 2016; Gaff et al. 2018).

Surely, our study had limitations. The cross-sectional design of our study did not allow for detecting PN prior to ART initiation nor for longitudinal comparison between antiretroviral naïve PLHIV and those on ART. Vibratory sense deficits may be caused also by other factors which may have confounding effects to the results. Only a few of our study participants were on protease inhibitor-based regimen so that the influence of this drug class may be undervalued. Difficult to quantify during the interview and thus equally underestimated is substance consumption (alcohol and tobacco). Since patients in the geographic setting usually seek medical attention late, also the information on the mean duration of HIV infection may be inaccurate. And finally, confounding effects with i.e., cell folate deficiency, thyroid dysfunction, hepatitis $\mathrm{B}$ and $\mathrm{C}$ infection, paraproteinemia, and any other potentially neurotoxic drugs cannot be entirely ruled out in the study approach.

During the investigational period, we felt vindicated by our approach of using the biothesiometer as a quantitative method to determine PN for comparative diagnosis. However, during the analyses phase, we sensed that complementing method(s) could have underpinned the case definition and hence the identified prevalence. We assumed both specificity and sensitivity of above $70 \%$; however, reports reveal a wider range (England et al. 2005; Gill et al. 2014). In our view, the biothesiometer should be accompanied by the observatory clinical assessment of PN, the application of the monofilament methodology, or even the Michigan neuropathy screening 
instrument (MNSI) which combines both symptoms and clinical examinations and had been validated by earlier studies to be accurate and reliable for screening PN (England et al. 2005; Yajnik et al. 2012; Gill et al. 2014; Woldeamanuel et al. 2016).

\section{Conclusions}

Derived from the observation during our routine clinical management of HIV-PN patients admitted to the Korle-Bu Teaching Hospital in Accra, Ghana, our assumption of a relatively high prevalence of PLHIV developing PN was in a way confirmed albeit the situation is less severe than presumed. Possibly, the phasing out of the NRTIs didanosine, stavudine, and zalcitabine in ART regulations by the Division of Public Health under Ghana Health Service in 2012/2013 fortunately reduced incidences of sensory neuropathies. Our results endorse inclusion of safer ART regimens, known to have less severe secondary effects, in respective national antiretroviral regulations and continuation of developing and testing better tolerable drugs against HIV infections.

The unveiled associations of PN with demographic, anthropometric, behavioral, and laboratory parameters confirmed earlier findings, above all body height and age from 34 years on as risk factors.

Our CD4 cell monitoring results, showing PN development associated with CD4 lymphocyte increase only triggered by ART but not in non-treated PLHIV, may hint towards possible antiretroviral secondary effects. Such would need to be particularly looked at in the sub-Saharan African setting which bears among the highest HIV/AIDS disease burden.

The biothesiometer is a reliable tool for quantitative PN diagnosis albeit the need for more robust and comparable assessment remains obvious.

The prevalence of still $17.7 \%$ of PN among PLHIV indicates that there is still a need for further reduction in morbidity of neuronal damage even in the post-stavudine era. Inacceptable complications, adding to the disability of the affected, can be counteracted with surveillance, early identification, and case management, requiring continued attention by the health system. Early health care seeking should be encouraged for both men and women, and PLHIV from the age of 30 on should be routinely screened for PN.

Acknowledgements We thank all the study participants for their consent to participate in the study. We also thank Adjoa Obo-Akwa and Rita Adu for their commitment and support during the study period and all supporting staff of the Department of Medicine Fevers Unit, Korle-Bu Teaching Hospital.

Authors' contributions PP and MK both shaped the conception and design of the study and contributed to proposal writing, data analysis, and manuscript writing and finalization. PP had the oversight of the data collection. EK contributed to the conception and design. VG and EK performed the data collection and analysis and contributed to the manuscript writing and review. WK, PA, and LG contributed to the conception and design, data collection and analysis, and manuscript review. All the authors have read and approved the final manuscript.

Funding information The study was largely funded by the HolgerPöhlmann Foundation.

\section{Compliance with ethical standards}

Conflict of interest The authors declare that they have no conflict of interest.

Ethical issues and data management This study was carefully considered for ethical issues before submission to the Ethical and Protocol Review Committee of the College of Health Sciences, University of Ghana, which has approved the study under the Protocol Identification Number MS-Et/M.9 - P 5.7/2012-13. Procedures were performed in compliance with relevant laws and institutional guidelines. Informed consent was obtained from each subject. The work has been carried out in accordance with the Declaration of Helsinki.

Data for this study were stored according to KBTH's policy, and results were blinded for use of the study in order to assure privacy rights of patients. The data obtained from this study are available and can be shared for justified purposes upon specific request and in accordance with the data management regulations of the College of Health Sciences in Ghana.

Open Access This article is distributed under the terms of the Creative Commons Attribution 4.0 International License (http:// creativecommons.org/licenses/by/4.0/), which permits unrestricted use, distribution, and reproduction in any medium, provided you give appropriate credit to the original author(s) and the source, provide a link to the Creative Commons license, and indicate if changes were made.

\section{References}

Afridi HI, Kazi TG, Talpur FN, Arain S, Arain SS, Kazi N, Panhwar AH, Brahman KD (2014) Evaluation of chromium and manganese in biological samples (scalp hair, blood and urine) of tuberculosis and diarrhea male human immunodeficiency virus patients. Clin Lab 60: 1333-1341

Ances BM, Vaida F, Rosario D, Marquie-Beck J, Ellis RJ, Simpson DM, Clifford DB, McArthur J, Grant I, McCutchan J, CNS HIV Antiretroviral Therapy Effects Research (CHARTER) Metabolic Study Group (2009) Role of metabolic syndrome components in HIV-associated sensory neuropathy. AIDS 23:2317-2322. https:// doi.org/10.1097/QAD.0b013e328332204e

Arenas-Pinto A, Thompson J, Musoro G et al (2016) Peripheral neuropathy in HIV patients in sub-Saharan Africa failing first-line therapy and the response to second-line ART in the EARNEST trial. J Neuro-Oncol 22:104-113. https://doi.org/10.1007/s13365-0150374-7

Beadles WI, Jahn A, Weigel R, Clutterbuck D (2009) Peripheral neuropathy in HIV-positive patients at an antiretroviral clinic in Lilongwe, Malawi. Trop Dr 39:78-80. https://doi.org/10.1258/td.2008.080213

Benevides M, Filho SB, Debona R, Bergamaschi ENC, Nunes JC (2017) Prevalence of peripheral neuropathy and associated factors in HIVinfected patients. J Neurol Sci 375:316-320. https://doi.org/10. 1016/j.jns.2017.02.011

Boulle A, Orrel C, Kaplan R, van Cutsem G, McNally M, Hilderbrand K, Myer L, Egger M, Coetzee D, Maartens G, Wood R, International 
Epidemiological Databases to Evaluate Aids in Southern Africa Collaboration (2007) Substitutions due to antiretroviral toxicity or contraindication in the first 3 years of antiretroviral therapy in a large South African cohort. Antivir Ther 12:753-760

Brew BJ, Tisch S, Law M (2003) Lactate concentrations distinguish between nucleoside neuropathy and HIV neuropathy. AIDS 17: 1094-1096. https://doi.org/10.1097/01.aids.0000060381.78202.fc

Canter JA, Haas DW, Kallianpur AR, Ritchie MD, Robbins GK, Shafer RW, Clifford DB, Murdock DG, Hulgan T (2008) The mitochondrial pharmacogenomics of haplogroup T: MTND2*LHON4917G and antiretroviral therapy-associated peripheral neuropathy. Pharmacogenomics J 8:71-77. https://doi.org/10.1038/sj.tpj.6500470

Chen H, Clifford DB, Deng L, Wu K, Lee AJ, Bosch RJ, Riddler SA, Ellis RJ, Evans SR (2013) Peripheral neuropathy in ARTexperienced patients: prevalence and risk factors. J Neuro-Oncol 19:557-564. https://doi.org/10.1007/s13365-013-0216-4

Cheng YJ, Gregg EW, Kahn HS, Williams DE, De Rekeneire N, Narayan KM (2006) Peripheral insensate neuropathy-a tall problem for US adults? Am J Epidemiol 164:873-880. https://doi.org/10.1093/aje/ kwj281

Cherry CL, Wadley AL, Kamerman PR (2012) Painful HIV-associated sensory neuropathy. Pain Manag 2:543-552. https://doi.org/10. 2217/pmt.12.67

Cherry CL, Wadley AL, Kamerman PR (2016) Diagnosing and treating HIV-associated sensory neuropathy: a global perspective. Pain Manag 6:191-199. https://doi.org/10.2217/pmt.15.65

Collins PY, Berkman A, Mestry K, Pillai A (2009) HIV prevalence among men and women admitted to a South African public psychiatric hospital. AIDS Care 21:863-867. https://doi.org/10.1080/ 09540120802626188

Cornblath DR, Hoke A (2006) Recent advances in HIV neuropathy. Curr Opin Neurol 19:446-450. https://doi.org/10.1097/01.wco. 0000245366.59446 .57

Ellis RJ, Rosario D, Clifford DB et al (2010) Continued high prevalence and adverse clinical impact of human immunodeficiency virusassociated sensory neuropathy in the era of combination antiretroviral therapy: the CHARTER study. Arch Neurol 67:552-558. https:// doi.org/10.1001/archneurol.2010.76

England JD, Gronseth GS, Franklin G, Miller RG, Asbury AK, Carter GT, Cohen JA, Fisher MA, Howard JF, Kinsella LJ, Latov N, Lewis RA, Low PA, Sumner AJ (2005) Distal symmetric polyneuropathy: a definition for clinical research: report of the American Academy of Neurology, the American Association of Electrodiagnostic Medicine, and the American Academy of Physical Medicine and Rehabilitation. Neurology 64:199-207. https://doi.org/10.1212/01. WNL.0000149522.32823.EA

Epi Info (2002) R2, Centers for Disease Control and Prevention, Atlanta, Georgia, USA

Evans SR, Clifford DB, Kitch DW, Goodkin K, Schifitto G, McArthur JC, Simpson DM (2008) Simplification of the research diagnosis of HIV-associated sensory neuropathy. HIV Clin Trials 9:434-439. https://doi.org/10.1310/het0906-434

Evans SR, Ellis RJ, Chen H, Yeh TM, Lee AJ, Schifitto G, Wu K, Bosch RJ, McArthur JC, Simpson DM, Clifford DB (2011) Peripheral neuropathy in HIV: prevalence and risk factors. AIDS 25:919928. https://doi.org/10.1097/QAD.0b013e328345889d

Fagbamigbe AF, Adebayo SB, Idemudia E (2016) Marital status and HIV prevalence among women in Nigeria: ingredients for evidencebased programming. Int $\mathrm{J}$ Infect Dis 48:57-63. https://doi.org/10. 1016/j.ijid.2016.05.002

Ferrari S, Vento S, Monaco S, Cavallaro T, Cainelli F, Rizzuto N, Temesgen Z (2006) Human immunodeficiency virus-associated peripheral neuropathies. Mayo Clin Proc 81:213-219. https://doi.org/ 10.4065/81.2.213

Ford D, Robins JM, Petersen ML, Gibb DM, Gilks CF, Mugyenyi P, Grosskurth H, Hakim J, Katabira E, Babiker AG, Walker AS (2015)
The impact of different CD4 cell-count monitoring and switching strategies on mortality in HIV-infected African adults on antiretroviral therapy: an application of dynamic marginal structural models. Am J Epidemiol 182:633-643. https://doi.org/10.1093/aje/kwv083

Forna F, Liechty CA, Solberg P, Asiimwe F, Were W, Mermin J, Behumbiize P, Tong T, Brooks JT, Weidle PJ (2007) Clinical toxicity of highly active antiretroviral therapy in a home-based AIDS care program in rural Uganda. J Acquir Immune Defic Syndr 44:456462. https://doi.org/10.1097/QAI.0b013e318033ffa1

Gaff J, Halstrom S, Temple SEL, Baltic S, Kamerman P, Price P (2018) Polymorphisms in P2X4R and CAMKK2 may affect TNFalpha production: implications for a role in HIV-associated sensory neuropathy. Hum Immunol 79:224-227. https://doi.org/10.1016/j.humimm.2018.02.002

Ghosh S, Chandran A, Jansen JP (2012) Epidemiology of HIV-related neuropathy: a systematic literature review. AIDS Res Hum Retrovir 28:36-48. https://doi.org/10.1089/AID.2011.0116

Gill HK, Yadav SB, Ramesh V, Bhatia E (2014) A prospective study of prevalence and association of peripheral neuropathy in Indian patients with newly diagnosed type 2 diabetes mellitus. J Postgrad Med 60:270-275. https://doi.org/10.4103/0022-3859.138750

Gomez-Olive FX, Angotti N, Houle B, Klipstein-Grobusch K, Kabudula C, Menken J, Williams J, Tollman S, Clark SJ (2013) Prevalence of HIV among those 15 and older in rural South Africa. AIDS Care 25: 1122-1128. https://doi.org/10.1080/09540121.2012.750710

Goullee H, Wadley AL, Cherry CL, Allcock RJ, Black M, Kamerman PR, Price P (2016) Polymorphisms in CAMKK2 may predict sensory neuropathy in African HIV patients. J Neuro-Oncol 22:508517. https://doi.org/10.1007/s13365-015-0421-4

Griswold GA, Evans S, Spielman L, Fishman B (2005) Coping strategies of HIV patients with peripheral neuropathy. AIDS Care 17:711-720. https://doi.org/10.1080/09540120412331336715

Gunthard HF, Saag MS, Benson CA et al (2016) Antiretroviral drugs for treatment and prevention of HIV infection in adults: 2016 recommendations of the International Antiviral Society-USA panel. JAMA 316:191-210. https://doi.org/10.1001/jama.2016.8900

Harrison TB, Smith B (2011) Neuromuscular manifestations of HIV/ AIDS. J Clin Neuromuscul Dis 13:68-84. https://doi.org/10.1097/ CND.0b013e318221256f

Hawkins C, Achenbach C, Fryda W, Ngare D, Murphy R (2007) Antiretroviral durability and tolerability in HIV-infected adults living in urban Kenya. J Acquir Immune Defic Syndr 45:304-310. https://doi.org/10.1097/QAI.0b013e318050d66c

Head KA (2006) Peripheral neuropathy: pathogenic mechanisms and alternative therapies. Altern Med Rev 11:294-329

Hendry LM, Wadley AL, Cherry CL, Price P, Lombard Z, Kamerman PR (2016) TNF block gene variants associate with pain intensity in Black Southern Africans with HIV-associated sensory neuropathy. Clin J Pain 32:45-50. https://doi.org/10.1097/AJP.0000000000000224

Hoffmann CJ, Fielding KL, Charalambous S, Sulkowski MS, Innes C, Thio CL, Chaisson RE, Churchyard GJ, Grant AD (2008) Antiretroviral therapy using zidovudine, lamivudine, and efavirenz in South Africa: tolerability and clinical events. AIDS 22:67-74. https://doi.org/10.1097/QAD.0b013e3282f2306e

Kallianpur AR, Hulgan T, Canter JA, Ritchie MD, Haines JL, Robbins GK, Shafer RW, Clifford DB, Haas DW (2006) Hemochromatosis (HFE) gene mutations and peripheral neuropathy during antiretroviral therapy. AIDS 20:1503-1513. https://doi.org/10.1097/01.aids. $0000237366.56864 .3 \mathrm{c}$

Kamerman PR, Wadley AL, Cherry CL (2012) HIV-associated sensory neuropathy: risk factors and genetics. Curr Pain Headache Rep 16: 226-236. https://doi.org/10.1007/s11916-012-0257-z

Kamerman PR, Wadley AL, Davis KD, Hietaharju A, Jain P, Kopf A, Meyer AC, Raja SN, Rice ASC, Smith BH, Treede RD, Wiffen PJ (2015) World Health Organization essential medicines lists: where are the drugs to treat neuropathic pain? Pain 156:793-797. https:// doi.org/10.1097/01.j.pain.0000460356.94374.a1 
Keswani SC, Pardo CA, Cherry CL, Hoke A, McArthur JC (2002) HIVassociated sensory neuropathies. AIDS 16:2105-2117

Kimanga DO, Ogola S, Umuro M, Ng'ang'a A, Kimondo L, Murithi P, Muttunga J, Waruiru W, Mohammed I, Sharrif S, de Cock KM, Kim AA, KAIS Study Group (2014) Prevalence and incidence of HIV infection, trends, and risk factors among persons aged 15-64 years in Kenya: results from a nationally representative study. J Acquir Immune Defic Syndr 66(Suppl 1):S13-S26. https://doi.org/10. 1097/QAI.0000000000000124

Kiwuwa-Muyingo S, Kikaire B, Mambule I, Musana H, Musoro G, Gilks CF, Levin JB, Walker AS (2014) Prevalence, incidence and predictors of peripheral neuropathy in African adults with HIV infection within the DART trial. AIDS 28:2579-2588. https://doi.org/10. 1097/QAD.0000000000000447

Kote GS, Bhat AN, Thajuddeen K, Ismail MH, Gupta A (2013) Peripheral insensate neuropathy-is height a risk factor? J Clin Diagn Res 7:296 301. https://doi.org/10.7860/JCDR/2013/5140.2751

Luma HN, Tchaleu BC, Doualla MS, Temfack E, Sopouassi VN, Mapoure YN, Djientcheu VD (2012) HIV-associated sensory neuropathy in HIV-1 infected patients at the Douala General Hospital in Cameroon: a cross-sectional study. AIDS Res Ther 9:35. https://doi. org/10.1186/1742-6405-9-35

Luma HN, Jua P, Donfack OT, Kamdem F, Ngouadjeu E, Mbatchou HB, Doualla MS, Mapoure YN (2018) Late presentation to HIV/AIDS care at the Douala General Hospital, Cameroon: its associated factors, and consequences. BMC Infect Dis 18:298. https://doi.org/10. 1186/s12879-018-3204-8

Margolis AM, Heverling H, Pham PA, Stolbach A (2014) A review of the toxicity of HIV medications. J Med Toxicol 10:26-39. https://doi. org/10.1007/s13181-013-0325-8

Maritz J, Benatar M, Dave JA, Harrison TB, Badri M, Levitt NS, Heckmann JM (2010) HIV neuropathy in South Africans: frequency, characteristics, and risk factors. Muscle Nerve 41:599-606. https://doi.org/10.1002/mus.21535

McArthur JC, Brew BJ, Nath A (2005) Neurological complications of HIV infection. Lancet Neurol 4:543-555. https://doi.org/10.1016/ S1474-4422(05)70165-4

Means AR, Risher KA, Ujeneza EL, Maposa I, Nondi J, Bellan SE (2016) Impact of age and sex on CD4+ cell count trajectories following treatment initiation: an analysis of the Tanzanian HIV treatment database. PLoS One 11:e0164148. https://doi.org/10.1371/journal.pone.0164148

Mehta SA, Ahmed A, Kariuki BW, Said S, Omasete F, Mendillo M, Laverty M, Holzman R, Valentine F, Sivapalasingam S (2010) Implementation of a validated peripheral neuropathy screening tool in patients receiving antiretroviral therapy in Mombasa, Kenya. Am J Trop Med Hyg 83: 565-570. https://doi.org/10.4269/ajtmh.2010.09-0629

Miller RF, Bunting S, Sadiq ST, Manji H (2002) Peripheral neuropathy in patients with HIV infection: consider dual pathology. Sex Transm Infect 78:462-463

Morgello S, Estanislao L, Simpson D, Geraci A, DiRocco A, Gerits P, Ryan E, Yakoushina T, Khan S, Mahboob R, Naseer M, Dorfman D, Sharp V, Manhattan HIV Brain Bank (2004) HIV-associated distal sensory polyneuropathy in the era of highly active antiretroviral therapy: the Manhattan HIV Brain Bank. Arch Neurol 61:546551. https://doi.org/10.1001/archneur.61.4.546

Ngassa Mbenda HG, Wadley A, Lombard Z, Cherry C, Price P, Kamerman P (2017) Genetics of HIV-associated sensory neuropathy and related pain in Africans. J Neuro-Oncol 23:511-519. https://doi. org/10.1007/s13365-017-0532-1

Nwabueze SA, Adogu PO, Adinma ED, Ifeadike CO, Nnebue CC, Ilika AL, Ikechebelu JI (2012) Determinants of subjective health status of HIV positive mothers in NAUTH Nnewi. Niger J Med 21:381-386

Phillips TJ, Brown M, Ramirez JD et al (2014) Sensory, psychological, and metabolic dysfunction in HIV-associated peripheral neuropathy: a cross-sectional deep profiling study. Pain 155:1846-1860. https:// doi.org/10.1016/j.pain.2014.06.014
Pillay P, Wadley AL, Cherry CL, Karstaedt AS, Kamerman PR (2018) Psychological factors associated with painful versus non-painful HIV-associated sensory neuropathy. AIDS Behav 22:1584-1595. https://doi.org/10.1007/s10461-017-1856-9

Robinson-Papp J, Morgello S, Vaida F, Fitzsimons C, Simpson DM, Elliott KJ, al-Lozi M, Gelman BB, Clifford D, Marra CM, McCutchan JA, Atkinson JH, Dworkin RH, Grant I, Ellis R (2010) Association of self-reported painful symptoms with clinical and neurophysiologic signs in HIV-associated sensory neuropathy. Pain 151:732-736. https://doi.org/10.1016/j.pain.2010.08.045

Scanlon ML, Vreeman RC (2013) Current strategies for improving access and adherence to antiretroviral therapies in resource-limited settings. HIV AIDS (Auckl) 5:1-17. https://doi.org/10.2147/HIV.S28912

Schutz SG, Robinson-Papp J (2013) HIV-related neuropathy: current perspectives. HIV AIDS (Auckl) 5:243-251. https://doi.org/10. 2147/HIV.S36674

Shaikh A, Bentley A, Kamerman PR (2013) Symptomatology of peripheral neuropathy in an African language. PLoS One 8:e63986. https:// doi.org/10.1371/journal.pone.0063986

Tumusiime DK, Venter F, Musenge E, Stewart A (2014a) Prevalence of peripheral neuropathy and its associated demographic and health status characteristics, among people on antiretroviral therapy in Rwanda. BMC Public Health 14:1306. https://doi.org/10.1186/ 1471-2458-14-1306

Tumusiime DK, Musabeyezu E, Mutimurah E, Hoover DR, Shi Q, Rudakemwa E, Ndacyayisenga V, Dusingize JC, Sinayobye JD, Stewart A, Venter FWD, Anastos K (2014b) Over-reported peripheral neuropathy symptoms in a cohort of HIV infected and uninfected Rwandan women: the need for validated locally appropriate questionnaires. Afr Health Sci 14:460-467. https://doi.org/10.4314/ahs.v14i2.24

UNAIDS (2016) Gobal aids update 2016. Joint United Nations Programme on HIV/AIDS

Wadley AL, Cherry CL, Price P, Kamerman PR (2011) HIV neuropathy risk factors and symptom characterization in stavudine-exposed South Africans. J Pain Symptom Manag 41:700-706. https://doi. org/10.1016/j.jpainsymman.2010.07.006

Wadley AL, Hendry LM, Kamerman PR, Chew CS, Price P, Cherry CL, Lombard Z (2015) Role of TNF block genetic variants in HIVassociated sensory neuropathy in black southern Africans. Eur J Hum Genet 23:363-368. https://doi.org/10.1038/ejhg.2014.104

Woldeamanuel YW, Kamerman PR, Veliotes DG, Phillips TJ, Asboe D, Boffito M, Rice AS (2016) Development, validation, and fieldtesting of an instrument for clinical assessment of HIV-associated neuropathy and neuropathic pain in resource-restricted and large population study settings. PLoS One 11:e0164994. https://doi.org/ 10.1371/journal.pone.0164994

World Health Organisation W (2015) Clinical guidelines: antiretroviral therapy consolidated guidelines on the use of antiretroviral drugs for treating and preventing HIV infection http://www.who.int/hiv/pub/ arv/chapter4.pdf

Yajnik CS, Kantikar VV, Pande AJ, Deslypere JP (2012) Quick and simple evaluation of sudomotor function for screening of diabetic neuropathy. ISRN Endocrinol 2012:103714-103717. https://doi. org $/ 10.5402 / 2012 / 103714$

Yeboah K, Puplampu P, Boima V, Antwi DA, Gyan B, Amoah AGB (2016) Peripheral sensory neuropathy in type 2 diabetes patients: a case control study in Accra, Ghana. J Clin Transl Endocrinol 5:2631. https://doi.org/10.1016/j.jcte.2016.07.001

Publisher's note Springer Nature remains neutral with regard to jurisdictional claims in published maps and institutional affiliations. 